\title{
Etlik Piliçlerde Kesim Sırasında Uygulanan Soğutma Yöntemlerinin Etin Bazı Kalite Özellikleri ve Raf Ömrü Üzerine Etkisi
}

\author{
Zeynep Kaçamaklı*, Mustafa Akşit \\ Adnan Menderes Üniversitesi Ziraat Fakültesi Zootekni Bölümü, Aydın \\ *e-posta: zkacamakli@adu.edu.tr; Tel: +90 (256) 7727023 / 2010; Faks : +90 (256) 7727233
}

\begin{abstract}
Özet
$\mathrm{Bu}$ çalışma, kesim işlemleri sırasında piliç karkaslarına uygulanan soğutma yöntemlerinin piliçlerin gögüs etinde gelişen bazı bakterilerin sayısına, $\mathrm{pH}_{(15-24)}$, renk ( $\mathrm{L}^{*}, \mathrm{a}^{*}$ ve $\left.\mathrm{b}^{*}\right)$ ve su kaybı gibi bazı et kalite özelliklerine olan etkilerini saptamak amacıyla yürütülmüştür. Çalışma ticari bir tavuk kesimhanesinde gerçekleştirilmiştir. Piliçler kesimden önce su soğutma, hava soğutma ve su+hava soğutma olmak üzere üç gruba ayrılmıştır. Piliç karkaslarına uygulanan soğutma yöntemlerinin, piliçlerin göğüs eti üzerinde gelişen mikroorganizmalara etkisini belirlemek için her gruptan alınan 10 (5 $\delta^{\wedge}: 5$ + $)$ piliç gögüs eti örneğinde $0,3,5,7$ ve 9. günlerde mezofilik ve psikrofil bakteri sayıları incelenmiştir. Ayrıca, kesim sonrası göğüs eti kalite özelliklerini değerlendirmek için her soğutma grubundan 30 (15 $\hat{\delta}^{\Uparrow}: 15$ 우), toplam 90 piliç karkası kullanılmıştır.

Araştırma sonuçları, hava ile soğutmanın depolanma sırasında, piliçlerin gögüs eti üzerinde bakterilerin gelişimini geciktirdiğini $(P<0.05)$ ve raf ömrünü olumlu yönde etkilediğini ortaya koymuştur. Soğutma yönteminin piliç etlerinin pH ve renk değeri üzerine etkisi önemli bulunmamıştır $(P>0.05)$. En fazla su kaybı hava ile soğutulan piliç etlerinde ortaya çıkmıştır. Ayrıca, incelenen özellikler üzerine cinsiyet etkisi önemli bulunmamıştır $(P>0.05)$.
\end{abstract}

Anahtar kelimeler: Soğutma yöntemi, et kalitesi, mikrobiyolojik kalite, raf ömrü

\section{The Effect of Chilling Methods Applied During Slaughter on Some Quality Characteristics and Shelf Life of Broiler Meat}

\begin{abstract}
A study was conducted to determine the effects of chilling methods during slaughter on some microbial growth on breast meat of chicken, and on some meat quality characteristics as $\mathrm{pH}\left({ }_{15-24}\right)$, color $\left(\mathrm{L}^{*}, \mathrm{a}^{*}\right.$ and $\left.\mathrm{b}^{*}\right)$ and drip loss. This study was carried out in a commercial poultry slaughterhouse. Before slaughtering, broiler chickens were divided into three groups as water chilling group, air chilling group and water + air chilling group. Numbers of bacteria of psychrophilic and mesophilic were examined at

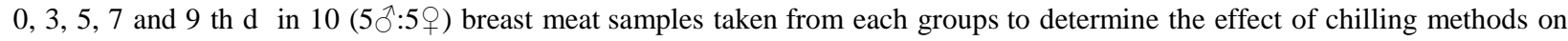
microbial growth in broiler meat. In addition, a total of 90 chicken carcasses (30 carcasses from each chilling group) were used to evaluate breast meat quality characteristics after slaughter.

Results of study presented that air chilling method delayed the bacterial growth on breast meat of chickens during the storage period and had a positive impact on shelf life $(P<0.05)$. The effect of chilling methods on $\mathrm{pH}$ and color of breast meat was not found significant $(P>0.05)$. The highest drip loss occurred when the air chilling method was applied. Features examined were not affected $(P>0.05)$ by bird sex.
\end{abstract}

Key word: Chilling methods, meat quality, microbial growth, shelf life.

\section{Giriş}

Piliç karkaslarında mikrobiyal gelişiminin geciktirilebilmesi, kesim işlemleri sırasında etin hızlı bir şekilde soğutulmasına bağlıdır. Bu nedenle piliçlerin iç organları çıkarıldıktan sonra ilk 4 saat içerisinde karkas sıcaklığının 4.4 'C' ye düşürülmesi gerekmektedir (Sanchez ve ark., 2002). Karkasın soğutulma süresi, soğutma sisteminin kritik parametrelerinden biri olmakla birlikte, buna paralel olarak karkas sıcaklığının hızlı bir şekilde ve kısa zamanda düşürülmesi de etin kalite özelliklerinden biri olan mikroorganizmaların gelişimini etkilemektedir. Salmonella görülme sıklığ hava ile soğutulmuş karkaslarda (\%33.3) su ile soğutulandan (\%56.6) daha yüksek bulunmuştur (Hargis ve ark., 2001)

Kesimhanelerde piliç karkaslarının soğutulması amaciyla su, hava ve son zamanlarda su+hava soğutma yöntemleri yaygın olarak kullanılmaktadır. Su ile soğutma piliç karkaslarında çapraz kontaminasyona yol açması ve fazla miktarda su kullanılması nedeniyle pek tercih edilmemektedir (Sanchez ve ark., 2002; Heuzo ve ark., 2007a ). Hava ile soğutmada karkaslar su absorbe 
etmediğinden etin su tutumu azalırken, kalitesi de artmaktadır. Jeong ve ark., (2011), su ile soğutulan piliçlerin (5.6) göğüs eti $\mathrm{pH}_{24}$ değerinin hava ile soğutulanlardan (5.5) daha yüksek olduğunu, hava ve evaporative yöntemlerle soğutulan karkasların $\mathrm{pH}_{24}$ değerleri arasında ise önemli farklılığın bulunmadığını ifade etmişlerdir.

Hava soğutma su kullanımını ve iş gücünü azaltmaktadır (Veerkamp, 1990; McKee, 2001). Ayrıca, hava ile soğutulan karkaslarda tüy yumuşatma suyunun düşük sıcaklıkta olması nedeniyle epidermis tabakası zarar görmediğinden deri rengi korunabilmektedir (Davies ve Board, 1998). Carol ve Alvaroda (2008), hava ve su soğutma uygulanan karkaslarda gelişen mikroorganizma sayısını inceledikleri çalışmada, su ile soğutulan karkaslarda çapraz kontaminasyona bağl1 daha fazla sayıda mikroorganizma geliştiğini ileri sürmüşlerdir. Son yıllarda ABD' deki kanatlı işletmelerinde hava ile soğutma yönteminin yaygınlaştığı ve hava ile soğutulan piliç eti tüketiminin arttığ1 görülmektedir (Carol ve Alvarado, 2008). Bunlara ek olarak evaporatif (su+hava) soğutma yöntemi de etkin soğutma yöntemleri arasında yer almaktadır (Northcutt ve ark., 2006).

$\mathrm{Bu}$ çalışmada, piliç kesimhanelerinde uygulanan farklı karkas soğutma yöntemlerinin piliç etinin bazı kalite özelliklerine ve raf ömrüne etkisi araştırılmıştır.

\section{Materyal ve Yöntem}

Ticari bir tavuk kesimhanesinde yürütülen bu çalışmada üç farklı karkas soğutma yöntemi uygulanmıştır. Her bir soğutma grubunda 30 piliç olmak üzere (15大̂:15ㅇ), toplam 90 piliç karkası kullanılmıştır. Kesim işlemleri sırasında, I. grupta yer alan piliçlere su soğutma, II. gruptakilere hava soğutma ve III. gruptakilere de kombine (su+hava) soğutma yöntemi uygulanmıştır. Karkaslar, su ile soğutmada, ön soğutma için 0 ile +4 ${ }^{\circ} \mathrm{C}$ sicaklıktaki su tankında (3.5-4lt/karkas) 20-25 dk bekletildikten sonra, son soğutma tankında 10-15 dk bekletilmiştir. Hava ile soğutmada karkaslar, sıcaklığı 0 ile $-4^{\circ} \mathrm{C}$ aralığında ve hava akım hızı $1.2 \mathrm{~m} / \mathrm{s}$ olan soğuk hava deposundaki raylara asılarak 80 ile $100 \mathrm{dk}$ kadar burada bekletilerek sıcaklıkları düşürülmüştür. $\mathrm{Su}+$ hava soğutma da ise, karkaslar ilk soğutma için +4 ${ }^{\circ} \mathrm{C}$ sıcaklığındaki su tanklarında $20 \mathrm{dk}$ bekletildikten sonra, soğuk hava deposundaki raylara asılarak $45 \mathrm{dk}$ bekletilmiştir. Soğutma gruplarına ait karkaslardan, mikroorganizma sayımı için sağ gögüs lobundan 100 gr, $\mathrm{pH}$, renk ve su kayıplarının belirlenmesi için ise sol göğüs lobundan 150 gr örnek alınmıştır.
Toplam aerob mezofilik ve psikrofilik mikroorganizma sayılarını belirlemek için her gruptan 10 adet $(5 q+5$ §) olmak üzere toplam 30 adet etlik piliç kullanılmıştır. Mikroorganizma ekimi dökme plak yöntemiyle PCA (Plate Count Agar) ile gerçekleştirilmiştir. Örnekler toplam aerob mezofilik canlı sayımı için $30{ }^{\circ} \mathrm{C}$ ' de 2 gün, toplam psikrofil canlı sayımı için $5{ }^{\circ} \mathrm{C}^{\prime}$ de 7 gün süre ile inkübe edilmiştir. Sayım işlemi 30-300 kuralına göre yapılmıştır (Swanson ve ark., 1992; FAO., 1992). Piliç etlerinde, soğutma yönteminin raf ömrüne etkisini incelemek amaciyla $0,3,5,7$ ve 9 . günlerde bakteri sayımları tekrarlanmıştır. Mikroorganizma sayım işlemi süresince et örnekleri buzdolabında $+4{ }^{0} \mathrm{C}$ 'de saklanmıştır.

Ayrıca, piliç etlerinde $\mathrm{pH}$ ölçümü, yarı katı et proplu Hanna 211 pH metre ile kesimden ilk $15 \mathrm{dk}$ ve kesimden 24 sa sonra olmak üzere iki defa yapılmıştır. Örnekler buzdolabı koşularında 24 sa bekletildikten sonra,Minolta Chroma Meter CR-300, kolorometre ile renk ölçümü yapılmıştır (Hunt ve ark., 1991). Su kayıplarının belirlenmesi için kesim yerinde ağırlıkları saptanarak streç filme sarılıp 2 gün süre ile $+4{ }^{\circ} \mathrm{C}$ ' de muhafaza edilen et örneklerinin depolama sonunda tekrar ağırlıkları belirlenmiştir. Çözdürme ve pişirme kayıpları için, derin dondurucuda 3 gün bekletildikten sonra dondurucudan çıkarılan örnekler oda koşullarında 12 saat süreyle çözdürmeye bırakılmıştır. Etler çözündükten sonra kâğıt havluyla kurulanarak kesim sonrası ağırlıkları belirlenmiştir. Bu örnekler $80{ }^{\circ} \mathrm{C}$ deki su banyosunda 30-45 dk pişirilmiştir. Pişirme işleminden sonra oda sıcaklığında 4 saat bekletilerek kurulanan örneklerin pişirme sonrası ağırlıkları saptanmıştır (Honikel,1997).

Çalışmada elde edilen toplam mikroorganizma sayılarına ait veriler logaritmik olarak transforme edilerek, et kalitesine ait veriler $\left(\mathrm{pH} 15, \mathrm{pH} 24, \mathrm{~L}^{*}, \mathrm{a}^{*}\right.$ ve $b^{*}$ ) ise doğrudan SPSS istatistik paket programının Genel Doğrusal Modelde yer alan Multivariate yöntemine göre analiz edilmiştir. Ortalamalar arasındaki farkların önemi Duncan testine göre değerlendirilmiştir. Grup içi cinsiyet farkının önemi SPSS istatistik paket programının Compare means kısmında yer alan T Test'i kullanılarak belirlenmiştir. (SPSS 19, 2011).

\section{Bulgular ve Tartışma}

Sonuçlar, cinsiyetin ele alınan özellikler üzerindeki etkisinin önemli olmadığını ortaya koymuştur. Bu nedenle bunlara sonuçlarda yer verilmemiştir.

Soğutma yöntemlerinin etkilerini belirlemeyi amaçlayan bu çalışmada, depolama sırasında $+4{ }^{\circ} \mathrm{C}$ de bekletilen 
Çizelge 1. Soğutma yöntemlerinin piliç göğüs eti toplam mezofilik (M) ve psikrofilik (P) bakteri sayıları (log cfu/g) üzerine etkileri

\begin{tabular}{|c|c|c|c|c|c|c|}
\hline \multicolumn{7}{|c|}{$\mathrm{G} u ̈ \mathrm{n} l$ e $\mathrm{r}$} \\
\hline Yöntem & & 0 & 3 & 5 & 7 & 9 \\
\hline \multirow[t]{2}{*}{$\mathrm{Su}$} & $\mathrm{P}$ & $0.0 \pm 0.0$ & $0.00 \pm 0.25^{\mathrm{a}}$ & $3.58 \pm 0.26$ & $5.41 \pm 0.32$ & $7.34 \pm 0.24^{\mathrm{b}}$ \\
\hline & M & $1.71 \pm 0.20$ & $2.30 \pm 0.19$ & $3.68 \pm 0.25^{\mathrm{ab}}$ & $5.30 \pm 0.28^{\mathrm{b}}$ & $7.12 \pm 0.26^{\mathrm{b}}$ \\
\hline \multirow[t]{2}{*}{ Hava } & $\mathrm{P}$ & $0.0 \pm 0.0$ & $0.00 \pm 0.25^{\mathrm{a}}$ & $3.26 \pm 0.26$ & $4.49 \pm 0.32$ & $6.47 \pm 0.24^{\mathrm{a}}$ \\
\hline & M & $1.94 \pm 0.20$ & $2.45 \pm 0.19$ & $3.09 \pm 0.25^{\mathrm{a}}$ & $4.48 \pm 0.28^{\mathrm{a}}$ & $6.27 \pm 0.26^{\mathrm{a}}$ \\
\hline \multirow[t]{2}{*}{ Su+ Hava } & $\mathrm{P}$ & $0.0 \pm 0.0$ & $0.97 \pm 0.25^{b}$ & $3.56 \pm 0.26$ & $5.38 \pm 0.32$ & $6.79 \pm 0.24^{\mathrm{ab}}$ \\
\hline & M & $2.25 \pm 0.20$ & $2.46 \pm 0.19$ & $4.21 \pm 0.25^{\mathrm{b}}$ & $5.52 \pm 0.28^{\mathrm{b}}$ & $6.71 \pm 0.26^{\mathrm{ab}}$ \\
\hline
\end{tabular}

a-c: Aynı sütunda farklı harf taşıyan gruplar arasındaki fark önemlidir $(\mathrm{p} \leq 0.05)$.

piliç göğüs etlerinde, su+hava grubu dışında 3. güne kadar psikrofil bakteriye rastlanmazken, bulgular 3 . günden sonra bu sayının arttığını ve 9 . günde pik yaptığı ortaya koymaktadır (Çizelge 1). Gallo ve ark. (1988), Regez ve ark. (1988) ve Hinton ve ark. (2004) piliç etlerinin bekletilmesi sirasında psikrofil bakteri sayısındaki önemli artışın, araştırma bulgularımızdakine benzer olarak depolamanın 6 . günden sonra gerçekleştiğini ileri sürmüşlerdir. Araştırma bulgularımız deneme sonu olan 9. günde ise hem psikrofil (7.34 log cfu $\mathrm{g}^{-1}$ ) hem de mezofil bakteriler sayıları açısından (7.12 $\left.\log \mathrm{cfu} \mathrm{\textrm {g } ^ { - 1 }}\right)$ su ile soğutulan karkaslarda daha yüksek, hava ile soğutulanlarda ise önemli düzeyde daha düşük sayıda bakteri geliştiğini göstermektedir (Çizelge 1). Tuncer ve Sireli (2008), bulgularımıza benzer şekilde buzdolabı koşullarında bekletilen piliç etlerinde gelişen psikrofil bakteriler (Pseudomanas spp.) üzerine hava ile soğutmanın su ile soğutmaya göre daha etkili olduğunu bildirmiştir. Su ile soğutulan karkaslarda, hava ile soğutulanlara göre daha fazla sayıda mikroorganizmanın gelişmesi su ile soğutmada karkasların soğuk su tankında bekletilmesi sırasında gerçekleşen çapraz bulaşmadan kaynakladığı düşünülebilir. Konu ile ilgili çalışmalarda hava ile soğutulan karkaslarda mikroorganizma yükünün daha düşük olduğu (Barbut, 2002; Sanchez ve ark., 2002) ve daha az sayıda aerobik bakteri ve koliform içermeleri nedeniyle de daha uzun raf ömrüne sahip olduklarını bildiren sonuçlar (Carol ve Alvaroda, 2008), araştırma bulgularımızı desteklemektedir.

Diğer taraftan, Berrang ve ark. (2008), su ile soğutulan karkaslarda (3.40 $\log$ cfug $\left.^{-1}\right)$ hava ile soğutulanlara (3.83 log cfu g ${ }^{-1}$ ) göre toplam mikroorganizma sayısını daha düşük bulmuştur. Araştırma bulgularımızla çelişki yaratan bu durumun soğutma suyunda klor bazlı dezenfektan kullanılmasından kaynaklanmış olabileceği düşünülmektedir.

Soğutma yöntemleri piliç etlerinin $\mathrm{pH}$ ve renk değerleri üzerinde önemli bir etki yaratmamıştır (Çizelge 2). Carol ve Alvarado (2008) hava ile Janardhanan (2011) su ile soğutmanın karkasların $\mathrm{pH}$ değerini yükselttiğini, ileri sürerken, diğer taraftan da araştırma bulgularımıza benzer olarak hava ve kombine yöntemle soğutulan karkasların $\mathrm{pH}$ değerleri arasındaki farkın önemli olmadığını belirtmişlerdir. Araştırma bulgularımızda olduğu gibi Fleming ve ark. (1991), Huezo ve ark. (2007b) ve Zhuang ve ark. (2009), su ve hava ile soğutmanın piliçlerin göğüs eti rengi üzerinde yarattığ etkinin önemli olmadığını belirtmişlerdir.

Bu çalışmada, göğüs etinin $L^{*}$ değeri su ile soğutulan karkaslarda daha yüksek olmakla birlikte soğutma yöntemlerinin et rengi üzerinde önemli etki yaratmadığı görülmektedir (Çizelge 2). Caroll ve Alvadora (2008), Jeong ve ark. (2011) ve Huezo ve ark. (2007b), su ile soğutulan karkasların göğüs etinde $L^{*}$ değerini,

Çizelge 2. Soğutma yöntemlerinin piliç göğüs eti kalite özellikleri üzerine etkisi

\begin{tabular}{lrrrrr}
\hline Yöntem & $\mathrm{pH}_{15}$ & $\mathrm{pH}_{24}$ & $\mathrm{~L}^{*}$ & $\mathrm{a}^{*}$ & $\mathrm{~b}^{*}$ \\
\hline $\mathrm{Su}$ & $6.39 \pm 0.04$ & $5.98 \pm 0.03$ & $55.84 \pm 0.91$ & $1.85 \pm 0.13$ & $-7.77 \pm 0.34$ \\
Hava & $6.48 \pm 0.04$ & $5.99 \pm 0.03$ & $54.44 \pm 0.90$ & $1.85 \pm 0.13$ & $-7.03 \pm 0.33$ \\
Su+ Hava & $6.46 \pm 0.04$ & $5.95 \pm 0.03$ & $54.59 \pm 0.97$ & $1.69 \pm 0.14$ & $-6.74 \pm 0.36$ \\
\hline
\end{tabular}


Çizelge 3. Farklı Yöntemlerle Soğutulan Piliç Etlerinde Ortaya Çıkan Bazı Kayıplar ( \% )

\begin{tabular}{lcccc}
\hline Yöntem & Ağılık kayb1 & Çözdürme kayb1 & Pişirme kayb1 & Su kayb1 \\
\hline Su & $3.51 \pm 0.28^{\mathrm{c}}$ & $19.03 \pm 0.47^{\mathrm{b}}$ & $22.60 \pm 0.69^{\mathrm{b}}$ & $14.15 \pm 0.86^{\mathrm{b}}$ \\
Hava & $-2.34 \pm 0.28^{\mathrm{a}}$ & $15.26 \pm 0.48^{\mathrm{a}}$ & $19.58 \pm 0.69^{\mathrm{a}}$ & $10.81 \pm 0.85^{\mathrm{a}}$ \\
$\mathrm{Su}+$ Hava & $1.91 \pm 0.30^{\mathrm{b}}$ & $16.14 \pm 0.51^{\mathrm{a}}$ & $21.51 \pm 0.75^{\mathrm{b}}$ & $12.23 \pm 0.92^{\mathrm{ab}}$ \\
\hline
\end{tabular}

a-c: Aynı sütunda, aynı uygulamada farklı harf taşıyan soğutma yöntemleri arasındaki fark önemlidir $(p \leq 0.05)$.

Janarhann (2011), hava ile soğutulan piliçlerin göğüs etinde $a^{*}$ ve $b^{*}$ değerini daha yüksek bulmuşlardır.

Piliç etlerinde ortaya çıkan bazı kayıplar üzerine karkas soğutma yöntemlerinin, etkisine bakıldığında, hava ile soğutmanın, soğutma sonrası ağırlık kaybı dışında, söz konusu kayıpları önemli düzeyde azalttı̆̆ görülmektedir (Çizelge 3). Hava ile soğutulan piliç karkaslarında \% -2.34'lik bir ağırlık kaybı söz konusu iken diğer gruplarda bir ağırlık kazancının olduğu anlaşılmaktadır. Ağırlık kazancının, piliç karkaslarının su dolu soğutma tanklarda bekletilmesi sirasinda absorbe etmiş oldukları sudan kaynaklandığı söylenebilir.

Araştırma bulgularımızla benzer olarak, hava ile soğutulan karkaslarda \% $\quad 0.8-2.5$ arasında ağırlık kaybının (Huezo ve ark., 2007a), su ile soğutulan karkaslarda ise \% 4.6-9.3 arasında ağırlık kazancının ortaya çıktığı bildirilmiştir (Huezo ve ark., 2007a; Zhuang ve ark., 2008). Öte yandan Mielnik ve ark. (1999) hava ve kombine yöntemle soğutulan karkaslarda nem içeriğinin benzer olduğunu, 24 sa bekletmeyle \% 1.8 oranında ağırlık kaybettiklerini bildirmişlerdir. Aynı çalışmada, deri ve göğüs eti nem içeriği ile pişirme kaybı hava ve kombine yöntemle soğutulan karkaslarda benzer bulunmuştur.

\section{Sonuc}

Kesimhanelerde uygulanan soğutma yöntemleri karkasların dış (kuruluk, nemlilik ve karkas renginde değişikliği) ve iç yüzeyinde (etin mukavemeti, pişirme kaybı ve kalitesi) çeşitli etkiler meydana getirebilmektedir (Mielnik ve ark., 1999; Alvarado 2008, Zhuang ve ark., 2008). Bu nedenle soğutma yöntemi, etin kalitesi ve raf ömrü açısından önem taşımaktadır. Soğutma yöntemlerine işletme ekonomisi ve et kalitesi açısından baktığımızda ise hava ile soğutmanın daha etkin olduğu görülmektedir. Su ile soğutmada ise karkasın su tutması etin kalitesini olumsuz etkilemekte ve mikroorganizma faaliyetlerine olanak vermesi nedeniyle raf ömrünün kısalmasına yol açmaktadır. Oysa hava ile soğumada karkasın su tutması söz konusu olmadığından et kalitesi korunabilmektedir (Veerkamp, 1990; McKee, 2001). Ayrıca, hava ile soğutma sırasında karkaslar arasında temasın olmaması kontaminasyonu engellediği için başlangıçta daha düşük bakteri yüküne sahip karkasların üretilmesi, raf ömrünün de daha uzun olmasına olanak vermektedir.

\section{Kaynaklar}

Barbut, S. 2002. Primary processing of poultry in Poultry Products Processing: An Industry Guide, 81-107.

Berrang, M. E., Meinersmann, R. J., Smith, D. P., Zhuang, H. 2008. The effect of chilling in cold air or ice water on the microbiological quality of broiler carcasses and the population of Campylobacterl. Poultry Sci. 87: 992-998.

Carol, C.D., Alvarado C.Z. 2008. Comparison of air and immersion chilling on meat quality and shelf life of marinated broiler breast fillets. Poultry Sci. 87: 368372.

Davies, A., Board, R. 1998 The microbiology of meat ve poultry. Andrew Dawis Ed., Ron Board, $1^{\text {st }}$ edition, London, UK.

Fleming, B. K., Froning, G. W., Yang, T. S. 1991. Heme pigment levels in chicken broilers chilled in ice slush and air. Poultry Sci. 70: 2197-2200.

FAO. 1992. Manual of food quality control. 4. Rev. 1. Microbiological Analysis. Food and Agricultural Organization of the United Nations, Rome, 43-56.

Gallo, L., Schmitt, R. E., Schmitt-Lorenz, W. 1988. Microbial spoilage of refrigerated fresh broilers. I. Bacterial flora and growth during storage. Lebensm.-Wiss. u.-Technol. 21: 216-223.

Hargis, B. M., Caldwell, D. J., Byrd, J. A. 2001. Microbiological pathogens: Live poultry considerations. Poultry Meat Processing. Sams, A. R. (ed.), CRC Press, USA, pp. 121-137

Honikel, K. 1997. Reference methods supported by OECD and their use in Mediterranean meat products. Food Chem. 59: 573-582.

Hinton, A., Cason, J. A., Ingram, K. D. 2004. Tracking spoilage bacteria in commercial poultry processing and refrigerated storage of poultry carcasses. Int. J. Food Microbiol. 91: 155-165.

Huezo, R., Smith, D. P., Northcutt, J. K., Fletcher, D. L. 2007a. Effect of immersion or dry air chillingon broiler carcass moisture retentionand breast fillet 
functionality. Poultry Res. 16: 438-447.

Huezo, R., Smith, D. P., Northcutt, J. K., Fletcher, D. L. 2007b. Effect of chilling method and deboning time on broiler breast filet quality. J. Appl. Poult. Res. 16: 537-545.

Hunt, M,C., Acton, J.C., Benedict, R, C., Calkins, C.R., Cornforth, D.P., Jeremiah, L,E., Olson, D.P., Salm, C.P., Savell, J.W., Shiwas, S.D. 1991. Guidelines for meat color evaluation. Chicago: American Meat Sci. Assoc. and National Live Stock and Meat Board.

Janardhanan, K. K. 2011. Evaluation of chilling methods on broiler carcass appearance, texture, sensory and microbial quality. Michigan State University. Master tezi. U.S.A.

Jeong, J. Y., Janardhanan, K. K, Booren, A. M, Karcher, D. M, Kang, I. 2011. Moisture content, processing yield, and surface color of broiler carcasses chilled by water, air, or evaporative air. Poultry Sci. 90: 687-693.

McKee, S. 2001. Chilling of broiler immersion and air. Watt Poultry Sci. 12: 18-24.

Mielnik, M. B., Dainty, R. H, Lundby, F., Mielnik, J. 1999. The effect of evaporative air chilling and storage temperature on quality and shelf life of fresh chicken carcasses. Poultry Sci. 78: 1065-1073

Northcutt, J. K., Cason, J. A., Smith, D. P., Buhr, R. J., Fletcher, D. L. 2006. Broiler carcass bacterial counts after immersion chilling using either a low or high volume of water. Poultry Sci. 85: 1802-1806.

Regez, P., Gallo, L., Schmitt, R.E., Schmitt Lorenz, W. 1988. Microbial spoilage of refrigerated fresh broilers. III. Effect of storage temperature on the microbial association of poultry carcasses. Lebensm.-Wiss. u.-Technol. 21: 229-233.

Sanchez, M. X., Fluckey, W. M., Brashears, M. M., McKee, S. R. 2002. Microbial profile and antibiotic susceptibility of Campylobacter spp. and Salmonella spp. in broilers processed in air-chilled and immersion-chilled environments. J. Food Prot. 65: 948-956.

SPSS, 2011. SPSS for Windows, Release 19.0, SPSS Inc.

Swanson, K., Busta, F.F., Peterson, E. H., Johnson., M. G. 1992. Colony counts method. Public health association. chapter 16: 239-249. Washington, D.C

Tuncer, B., Sireli, U. T. 2008. Microbial growth on broiler carcasses stored at different temperatures after air or water-chilling. Poultry Sci. 87: 793-799.

Veerkamp, C. H. 1990. Chilling of poultry and poultry products. 8 in Chilled Foods: The State of Art. T. R.Gormley, ed. Elsevier Appl. Sci. S. 147-15, New York.

Zhuang, H., Savage, E.M , Smith, D.P, Berrang, M.E. 2008. Effect of dry-air chilling on warner-bratzler shear force and water-holding capacity of broiler breast meat deboned four hours postmortem. International Journal of Poultry Sci. 7(8): 743-748.

Zhuang, H., Savage, E.M. 2009. Variation and pearson correlation coefficients of warner-bratzler shear force measurements within broiler breast fillets. Poult. Sci. 88: 214-220. 